ARTICLE

\title{
Synthesis of bridged tricyclo[5.2.1.01,5]decanes via nickel-catalyzed asymmetric domino cyclization of enynones
}

\author{
Jiachang Chen ${ }^{1}$, Yiming Wang ${ }^{1}$, Zhengtian $\operatorname{Ding}^{1} \&$ Wangqing Kong ${ }^{1 凶}$
}

The restricted availability, expense and toxicity of precious metal catalysts such as rhodium and palladium challenge the sustainability of synthetic chemistry. As such, nickel catalysts have garnered increasing attention as replacements for enyne cyclization reactions. On the other hand, bridged tricyclo[5.2.1.01,5]decanes are found as core structures in many biologically active natural products; however, the synthesis of such frameworks with high functionalities from readily available precursors remains a significant challenge. Herein, we report a nickel-catalyzed asymmetric domino cyclization reaction of enynones, providing rapid and modular synthesis of bridged tricyclo[5.2.1.01,5]decane skeletons with three quaternary stereocenters in good yields and remarkable high levels of regio- and enantioselectivities (92-99\% ee).

\footnotetext{
${ }^{1}$ The Center for Precision Synthesis (CPS), Institute for Advanced Studies (IAS), Wuhan University, 430072 Wuhan, People's Republic of China.

凶email: wqkong@whu.edu.cn
} 
W ith the growing concerns about environmental sustainability, the development of elegant methodologies for efficient and concise synthesis of complex bioactive natural and pharmaceutical products in a step-, atom- and redoxeconomic manner has received widespread attention. One of the most effective approaches to achieve such a goal is to develop catalytic asymmetric domino reactions in which multiple bondmaking events occur in one-pot, and complex chiral compounds with multi-stereogenic centers are generated from easily accessible precursors ${ }^{1,2}$. Consequently, significant efforts have been directed towards the development of asymmetric domino reactions, where the focus has been on the efficient synthesis of biologically important and highly functionalized chiral carbo- and heterocyclic compounds. In this context, the bridged tricyclo [5.2.1.0 $0^{1,5}$ ]decanes are found as core structures in many bioactive natural products, including Schincalide $\mathrm{A}^{3}$ and Illisimonin $\mathrm{A}^{4}$ (Fig. 1). Despite their importance, the bridged tricyclo[5.2.1.0 $0^{1,5}$ ] decane remain an elusive skeleton, and the development of which has been clearly underexploited ${ }^{5-7}$. Only recently, Rychnovsky's group reported the first total synthesis of Illisimonin A, in which the key tricyclic core was constructed by Diels-Alder reaction, and enantioselective control of this transformation has not yet been achieved ${ }^{8}$. The limited output for these challenging molecules may be due to the difficulty in asymmetric synthesis of the bridged tricyclo[5.2.1.0 $0^{1,5}$ decane core ${ }^{9-12}$, which hinders any further study on their potential bioactive properties. Therefore, a general approach that enables the modular and enantioselective synthesis of this key skeleton is highly desired and sought-after.

Transition metal-catalyzed asymmetric domino cyclization of 1, n-enynes represents a powerful synthetic tool to rapidly assemble chiral carbo- and heterocyclic compounds. Traditionally used precious metal catalysts based on $\mathrm{Rh}$, Ir, and $\mathrm{Pd}$, etc., have been widely used in such transformations ${ }^{13-25}$. However, they are very expensive and their reserves are declining, thus limiting their wide-scale industrial applications. As such, increasing attention has been focused on the development and use of earth-abundant and sustainable element, especially nickel catalysts, to replace these highly expensive and scarce metals in 1,n-enyne cyclization. However, the reaction is typically restricted to the use of activated alkenes, and the regioselectivity is controlled by the formation of a five-membered ring nickelacyclic intermediate ${ }^{26,27}$ (Fig. 2a). Recently, Lam et al. developed Ni-catalyzed asymmetric coupling cyclization of aryl-substituted alkynes with ketones $^{28}$ (Fig. 2b). We envisioned that the introduction of a 1,3-cyclopentanedione functionality on the 1,6-enyne moiety might facilitate a domino arylnickelation of alkyne/Heck cyclization with alkene/nucleophilic addition to ketone sequence, and therefore provides an expedient access to biologically important bridged tricyclo [5.2.1.0 $0^{1,5}$ ] decanes (Fig. 2c).

However, to realize the above conceptually simple yet attractive reaction, many challenging problems need to be addressed. The first is to control the regioselectivity of the 1,2-addition of the arylnickel species to the alkyne moiety ${ }^{29-33}$. since the regioselectivity we expected is contrary to that reported by $\mathrm{Lam}^{28}$. The second is to control the enantioselectivity of the Heck-cyclization

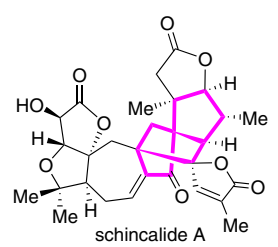

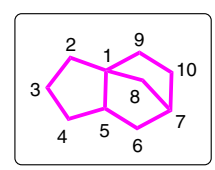

Tricyclo[5.2.1.0 $\left.0^{1,5}\right]$ decane

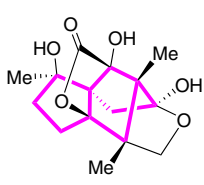

illisimonin A
Fig. 1 Representative examples of bioactive compounds. Bridged tricyclo $\left[5 \cdot 2 \cdot 1.0^{1,5}\right]$ decane scaffolds are structural cores in many natural products. process. Another challenge is that ketones are more electrophilic than unactivated alkenes, the direct cyclization of alkynes and ketones may take place preferentially, while unactivated alkenes do not participate in the cyclization process ${ }^{34-50}$.

Herein, we report catalytic enantioselective construction of bridged tricyclo[5.2.1.0 $0^{1,5}$ ]decanes with multiple quaternary stereocenters by $\mathrm{Ni}$-catalyzed domino coupling cyclization of an alkyne, an alkene and a ketone in a highly regio- and enantioselective fashion. This domino strategy not only has the advantage of being efficient, simple and starting from easily accessible precursors, but also provides the desired targets with two additional functional sites (a ketone and a fully substituted double bond), which could be easily used for diversity-oriented synthesis. This work documents a practical, catalytic enantioselective (92-99\% ee) approach to the most diverse set of bridged tricyclo $\left[5 \cdot 2 \cdot 1.0^{1,5}\right]$ decanes reported to-date.

\section{Results}

Reaction development. According to the reaction design shown in Fig. 2c, we began with an investigation of the model reaction for the construction of bridged tricyclo[5.2.1.0 $0^{1,5}$ ]decanes using the 1,3-cyclopentanedione tethered 1,6-enyne la as substrate, which can be easily prepared by a two-step sequence consisting of the reductive Knoevenagel condensation of commercially available cyclopentane-1,3-dione with alkynals ${ }^{51,52}$ followed by allylation with allyl halides. The reaction was first conducted with 10 mol \% of Ni(OAc) $)_{2} .4 \mathrm{H}_{2} \mathrm{O}$ and $12 \mathrm{~mol} \%$ of (S)-phenyl-Phox (L1) as catalyst in $\mathrm{MeCN}$. As anticipated, the cyclization of 1 a to 4 aa $(60 \%)$ was the major product of the reaction ${ }^{28}$, in which unactivated alkene was not involved, and only trace amount of the desired 3aa could be observed (Table 1, entry 1). The formation of 4 aa could not be mitigated and remained the main reaction pathway by using $\mathrm{MeOH}, \mathrm{DMF}$ or toluene as solvent (Table 1, entries 2-4), which reinforces the notion that the domino cyclization of 1a to bridged tricyclo[5.2.1.0 ${ }^{1,5}$ ]decane 3 aa would be far from trivial.

To suppress the formation of undesired $\mathbf{4 a a}$, it is necessary to activate the double bond. Interestingly, the desired product 3 aa was afforded in $33 \%$ yield and $71 \%$ ee when the reaction was performed in TFE as solvent (Table 1, entry 5). Subsequently,
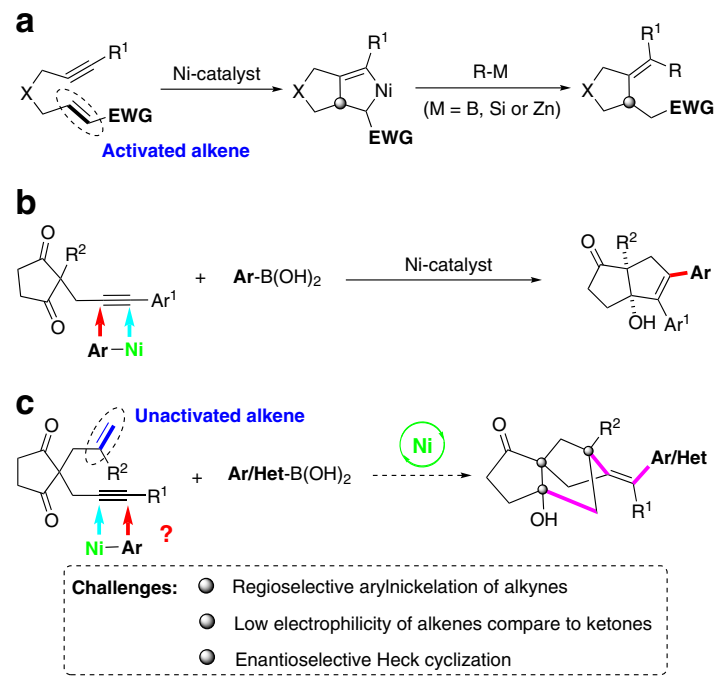

Fig. 2 Reaction design. a Ni-catalyzed coupling cyclization of an alkyne and an activated alkene; $\mathbf{b} \mathrm{Ni}$-catalyzed asymmetric coupling cyclization of an alkyne and a ketone; c Working hypothesis for bridged tricyclo[5.2.1.01,5] decanes synthesis via coupling cyclization of an alkyne, an alkene and a ketone. 


\section{Table 1 Optimization of reaction conditions ${ }^{\mathrm{a}}$.}

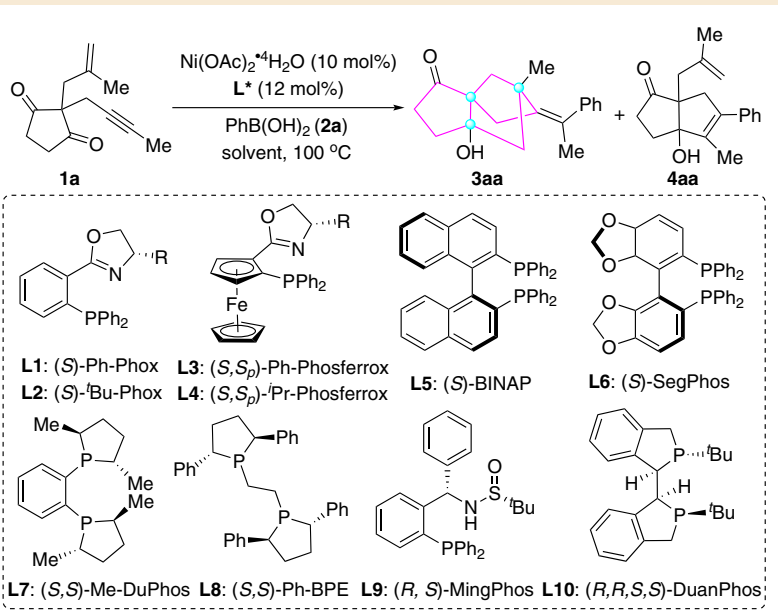

\begin{tabular}{llllll}
\hline Entry & Ligand & Solvent & $\begin{array}{l}\text { Yield of } \\
\text { 4aa (\%) }\end{array}$ & $\begin{array}{l}\text { Yield of } \\
\text { 3aa (\%) }\end{array}$ & $\begin{array}{l}\text { ee of } \\
\text { 3aa (\%) }\end{array}$ \\
\hline 1 & L1 & MeCN & 60 & Trace & - \\
2 & L1 & MeOH & 54 & Trace & - \\
3 & L1 & DMF & 12 & Trace & - \\
4 & $\mathbf{L 1}$ & Toluene & 5 & Trace & - \\
5 & $\mathbf{L 1}$ & TFE & 12 & 33 & 71 \\
6 & $\mathbf{L 2}$ & TFE & Trace & 41 & 65 \\
7 & $\mathbf{L 3}$ & TFE & 12 & 42 & 76 \\
8 & L4 & TFE & 9 & 46 & 75 \\
9 & $\mathbf{L 5}$ & TFE & 24 & 26 & 60 \\
10 & $\mathbf{L 6}$ & TFE & 20 & Trace & - \\
11 & $\mathbf{L 7}$ & TFE & Trace & 12 & 25 \\
12 & $\mathbf{L 8}$ & TFE & Trace & Trace & - \\
13 & $\mathbf{L 9}$ & TFE & 37 & Trace & - \\
14 & $\mathbf{L 1 0}$ & TFE & $<1$ & 77 & 98 \\
\hline
\end{tabular}

TFE 2,2,2-Trifluoroethanol.

Reaction condition: $\mathbf{1 a}(0.1 \mathrm{mmol}), \mathbf{2 a}$ ( 2 equiv), $\mathrm{Ni}(\mathrm{OAc})_{2} \cdot 4 \mathrm{H}_{2} \mathrm{O}$ ( 0.1 equiv), ligand $(0.12$

equiv), TFE $(1 \mathrm{~mL})$ at $100^{\circ} \mathrm{C}$ for $48 \mathrm{~h}$

byields of isolated products.

'Determined by HPLC on a chiral stationary phase.

different chiral Phox-type ligands L2-L4 were screened, the yields and ee values of 3aa remained moderate (Table 1, entries 6-8). To further improve the yield and enantioselectivity, various bidentate phosphine ligands such as (S)-BINAP (L5), (S)-SegPhos (L6), $(S, S)$-Me-DuPhos (L7), $(S, S)$-Ph-BPE (L8) and $(R, S)$-Ming-Phos (L9) were investigated. Unfortunately, neither the yields nor the enantioselectivities were improved (Table 1, entries 9-13). Excitingly, 3aa was obtained in $77 \%$ yield and $98 \%$ ee when a conformationally rigid P-stereogenic bis(phospholane) ligand L10 $\left(1 R, 1^{\prime} R, 2 S, 2^{\prime} S\right.$-Duanphos) ${ }^{53}$ was used (Table 1, entry 14).

The $E / Z$ configuration of the double bond and the absolute configuration of three newly formed quaternary stereocenters in 3aa were unambiguously assigned by X-ray crystal crystallography (Fig. 3).

Substrate scope. With optimal reaction conditions in hand, we first investigated the effect of various aryl-boron reagents, such as $\mathrm{PhB}(\mathrm{OH})_{2}, \mathrm{PhBPin}$ (phenylboronic acid pinacol ester), $\mathrm{PhBF}_{3} \mathrm{~K}$ and $(\mathrm{PhBO})_{3}$ (phenylboroxine) (Fig. 4a). Interestingly, all these aryl-boron reagents are compatible. Among them, the $\mathrm{Ph}-\mathrm{B}(\mathrm{OH})_{2}$ performed best comprehensively. The compatibility of the transformation with various (hetero)arylboronic acids was then evaluated in a robustness screening. A variety of para-substituted arylboronic acids could undergo tandem cyclization to provide

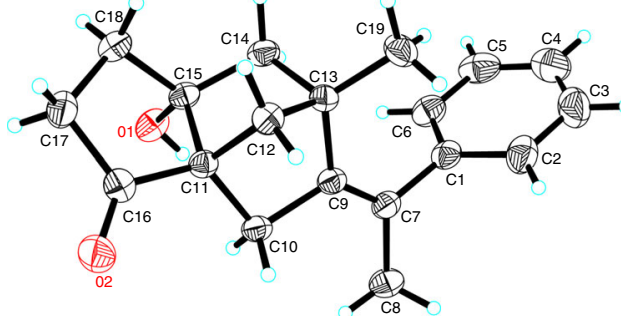

Fig. 3 Absolute configuration. ORTEP representation of the product $\mathbf{3 a a}$.

the target bridged tricyclo[5.2.1. $\left.0^{1,5}\right]$ decanes 3aa-3ao in $45-80 \%$ yields and $97-99 \%$ ee. All of these meta- and ortho-substituted arylboronic acids proceeded smoothly, providing the corresponding products 3ap-3ar in $74-82 \%$ yields and $96-99 \%$ ee. Notably, a series of synthetic valuable functional groups such as ether (3ac), free hydroxyl (3ad), chloride (3ae), bromide (3af), trifluoromethyl (3ag), cyano (3ah), sulfonyl (3ai), trifluoromethoxyl (3aj), nitro (3ak), aldehyde (3al), ketone (3am), amide (3an), ester (3ao), iodide (3ap) and fluoride (3aq and 3ar) were all well-tolerated. In addition, various (hetero)arylboronic acids was also investigated. Naphthalene (3as), dibenzothiophene (3at) and dibenzofuran (3au) were successfully incorporated into the desired products in $62-69 \%$ yields and $93-95 \%$ ee. Remarkably, pyrimidine was perfectly accommodated to furnish $\mathbf{3 a v}$ in $66 \%$ yield with $98 \%$ ee, which exhibits a wide variety of biological activities $^{54}$. Another interesting feature is that estrone could also be engaged in this route to afford the desired product 3aw in good yield and high diastereoselectivity ( $80 \%$ yield, $>20 / 1$ d.r.), thus demonstrating the robustness and generality of this methodology for the modification of complex biologically active molecules. However, no reaction was observed using an alkyl or alkenyl boronic acids.

Next, the substrate scope of enynone $\mathbf{1}$ was explored in reactions with (4-(methylsulfonyl)phenyl)boronic acid $\mathbf{2 i}$, which furnished products $\mathbf{3 b i}$-3oi in synthetic useful yields and $92-99 \%$ ee (Fig. 4b). We first studied the influence of the substituents at the alkyne terminus $\left(\mathrm{R}^{1}\right)$. The aryl group having an electrondonating or electron-withdrawing group at the alkyne terminus was found to be compatible, leading to the corresponding products 3 bi-3di in $57-61 \%$ yields and $97-99 \%$ ee. A dibenzofuran substituent which is very useful structural unit in organofunctional materials, could be successfully incorporated into the product 3ei (57\% yield, 99\% ee). Moreover, estrone substituted substrate could also be employed in this type of reaction sequence to provide the desired $\mathbf{3 f}$ in high diastereoselectivity (>20/1 d.r.). The reaction is not limited to aryl group at the alkyne terminus, and alkyl-substituted alkynes such as npentyl, benzyl, allyl and those functionalized with $\mathrm{CH}_{2} \mathrm{OTBS}$ and $\mathrm{CH}_{2} \mathrm{OBz}$ were also suitable substrates. It is noteworthy that $\mathbf{1 1}$ bearing a free hydroxyl group could be efficiently converted to 3li in $58 \%$ yield with $95 \%$ ee. However, terminal alkyne provides complex mixtures of unidentified products. Then, we investigated the influence of substituents on the alkene moiety $\left(R^{2}\right)$. The introduction of a phenyl group at $\mathrm{C}_{2}$ of the propene moiety did not preclude the transformation, producing $3 \mathbf{~ m i}$ in $55 \%$ yield with $96 \%$ ee. A methoxymethyl group was performed uniformly to give 3 ni in $70 \%$ yield and $98 \%$ ee at this position. Interestingly, substrate 10 bearing an ester group on the double bond was also amenable to this transformation, giving the desired 3oi in outstanding enantioselectivity ( $99 \%$ ee).

This transformation is not restricted to cyclic 1,3-diketone tethers, as substrate $\mathbf{1 p}$ containing acyclic 1,3-diketone tethered 

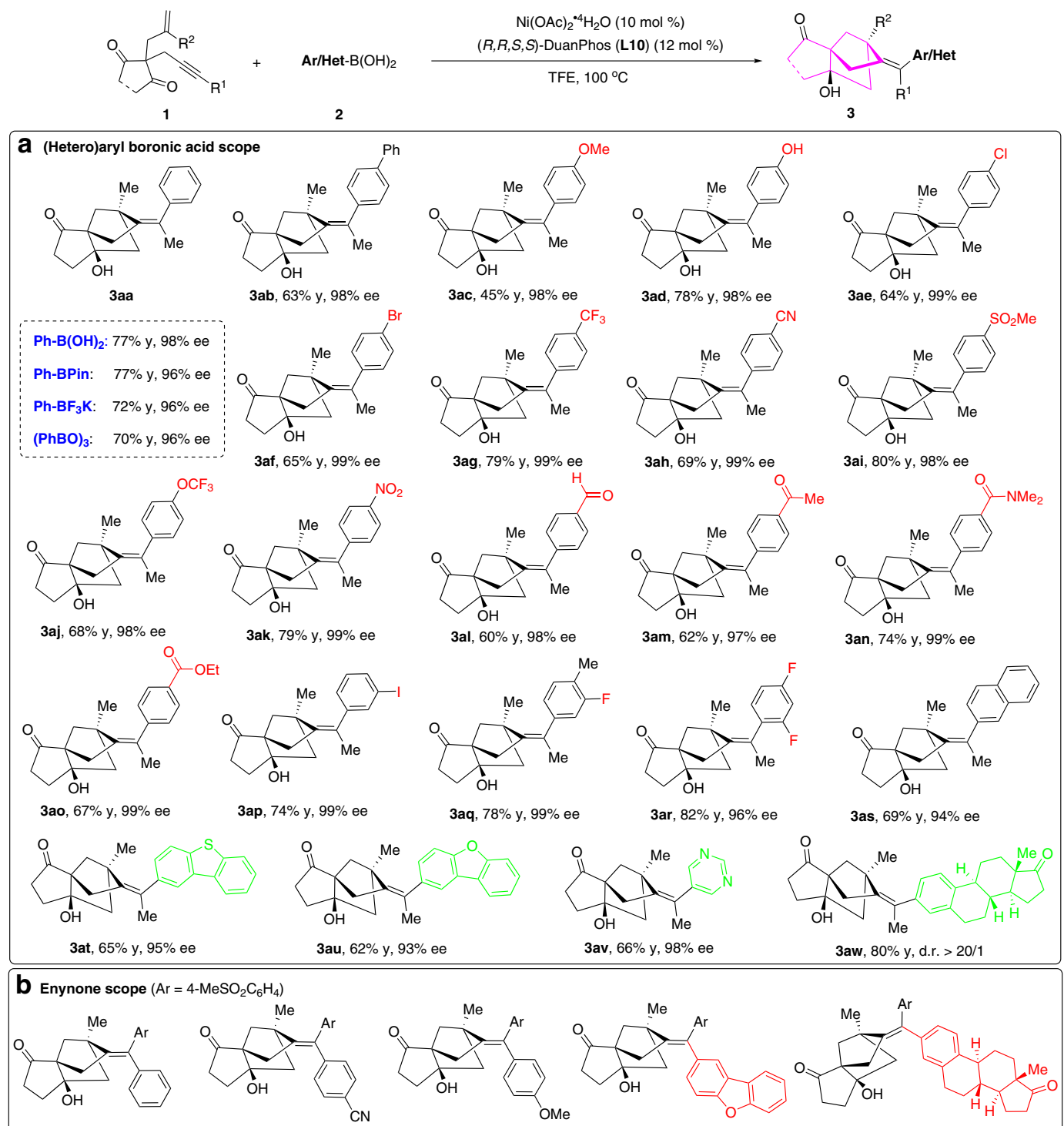

3bi, $61 \%$ y, $99 \%$ ee

3ci, $57 \%$ y, $99 \%$ ee

3di, $61 \%$ y, $97 \%$ ee

3ei, $57 \%$ y, $99 \%$ ee

3 fi, $56 \%$ y, d.r. $>20 / 1$
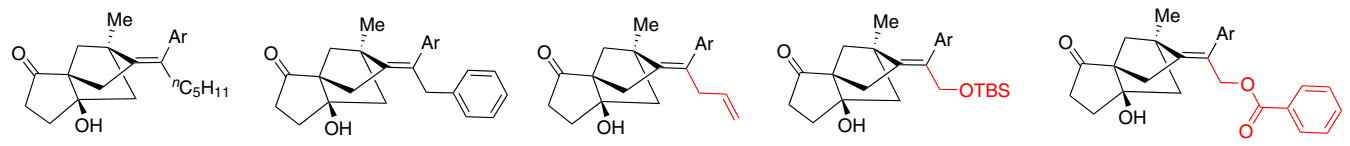

3gi, $88 \%$ y, $98 \%$ ee

3hi, $79 \%$ y, $92 \%$ ee

$3 \mathrm{ii}, 58 \%$ y, $98 \%$ ee

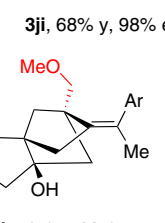

3ki, $81 \%$ y, $98 \%$ ee

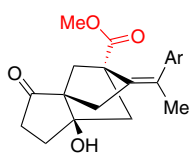

3li, $58 \%$ y, $95 \%$ ee

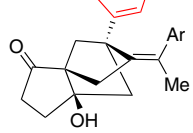

$3 \mathrm{mi}, 55 \%$ y, $96 \%$ ee

3ni, $70 \%$ y, $98 \%$ ee

3oi, $50 \%$ y, $99 \%$ ee

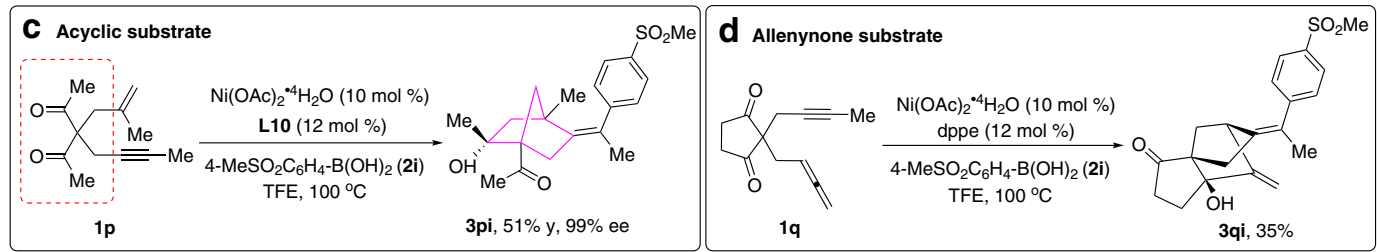

Fig. 4 Substrate scope. a (Hetero)arylboronic acid scope. b Enynone scope. c Acyclic substrate. d Allenynone substrate. 
a

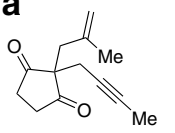
1a $0.50 \mathrm{~g}(2.5 \mathrm{mmol})$
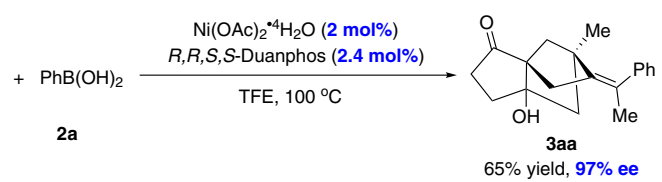

b
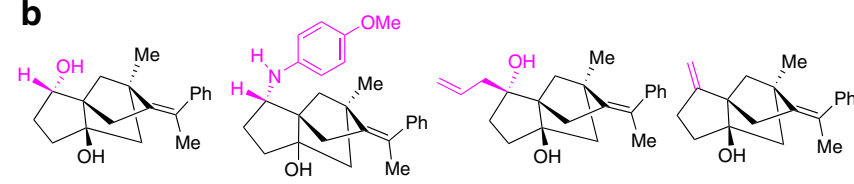

$5(93 \%,>20 / 1$ d.r. $)$ $6(70 \%,>20 / 1$ d.r. $)$
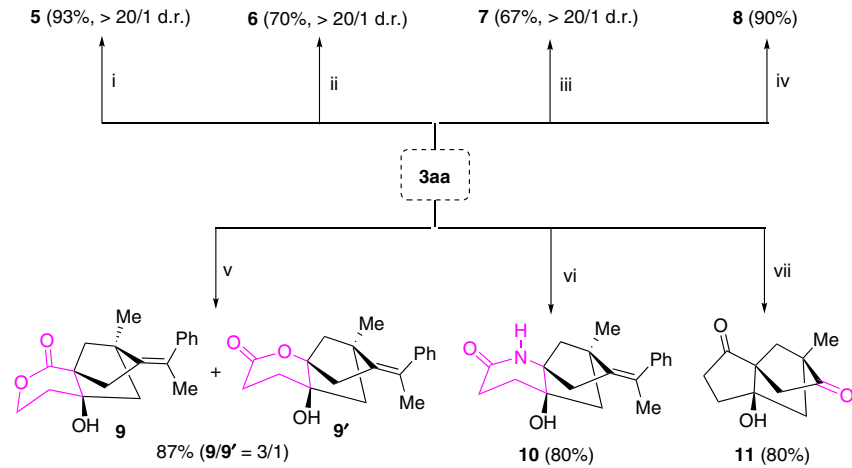

Fig. 5 Half-gram scale reaction and synthetic manipulations. a Half-gram scale reaction. b Synthetic applications. (i) $\mathrm{NaBH}_{4}, \mathrm{EtOH}, \mathrm{O}^{\circ} \mathrm{C} \sim$ rt; (ii) 4-methoxyaniline (3 equiv), $\mathrm{NaBH}_{3} \mathrm{CN}, \mathrm{MeOH}$, rt; (iii) allylMgBr, THF, -78 ${ }^{\circ} \mathrm{C}$-rt; (iv) $\mathrm{PPh}_{3} \mathrm{MeBr},{ }^{\mathrm{t}} \mathrm{BuOK}, \mathrm{THF}, 0^{\circ} \mathrm{C}$-rt; (v) $\mathrm{m}$-CPBA, $\mathrm{NaHCO}_{3}, \mathrm{DCM}$, rt; (vi) $\mathrm{NaN}_{3}, \mathrm{TFA} / \mathrm{H}_{2} \mathrm{O}=4 / 1,70^{\circ} \mathrm{C}$; (vii) $\mathrm{O}_{3} / \mathrm{PPh}_{3}, \mathrm{DCM},-78^{\circ} \mathrm{C}$-rt. $\mathrm{m}$ CPBA m-chloroperoxybenzoic acid, TFA trifluoroacetic acid.

1,6-enyne is also highly effective. As shown in Fig. 4c, the highly functionalized bicyclo[2,2,1]heptane derivative 3 pi bearing three quaternary stereocenters could also be efficiently constructed in $99 \%$ ee. It is worth noting that this bicyclo[2.2.1]heptane ring system is also a very important skeleton found in many pharmacologically active molecules ${ }^{55-57}$.

We further prepared 1,3-cyclopentanedione tethered 1,6-diene substrate, however, the expected product was not obtained. Interestingly, substrate $\mathbf{1 q}$ possessing allenyne tether could undergo an analogous cyclization reaction to afford the tricyclo [5.2.1.0 ${ }^{1,5}$ ]decane 3qi (Fig. 4d).

Synthetic applications. We carried out a $0.5 \mathrm{~g}$ scale reaction of $1 \mathrm{a}$ and found that the chiral Ni-catalyst loading as low as $2.0 \mathrm{~mol} \%$ was sufficient to provide 3 aa in $65 \%$ yield with $97 \%$ ee, thus revealing the practical applicability of this $\mathrm{Ni}$-catalyzed domino reaction (Fig. 5). To further demonstrate the synthetic benefit of our domino cyclization, Post-modifications on the tricyclo [5.2.1. $0^{1,5}$ ]decane skeleton were performed (Fig. 5). Compound 3aa could undergo a diastereoselective reduction by $\mathrm{NaBH}_{4}$ to form the corresponding alcohol $\mathbf{5}$ in $93 \%$ yield. Under reductive amination conditions with $\mathrm{NaBH}(\mathrm{OAc})_{3}$ and 4-methoxyaniline, 3aa was converted into amine 6 in $70 \%$ yield with $>20 / 1$ diastereoselectivity. A further diastereoselective 1,2-addition of allylMgBr to $3 \mathbf{a a}$ afforded the allyl alcohol 7 in $67 \%$ yield. Moreover, olefination of the ketone moiety of $3 \mathrm{aa}$ with $\mathrm{PPh}_{3} \mathrm{MeBr}$ via the Wittig reaction gave a new alkene $\mathbf{8}$ in $90 \%$ yield. We further took advantage of the ketone moiety to generate the bridged tricyclic lactones $\mathbf{9}$ and 9' with a ratio of 3:1 through the Baeyer-Villiger oxidation in the presence of $m$-CPBA. Interestingly, bridged tricyclic lactam 10 could also be selectively obtained in $80 \%$ yield via the Schmidt reaction with $\mathrm{NaN}_{3}$. Finally, the tetrasubstituted double bond was

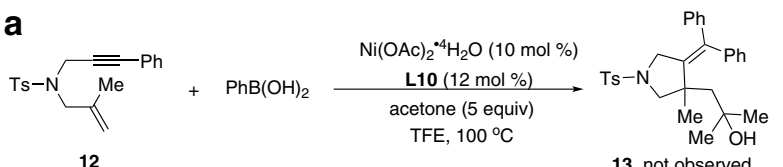

b
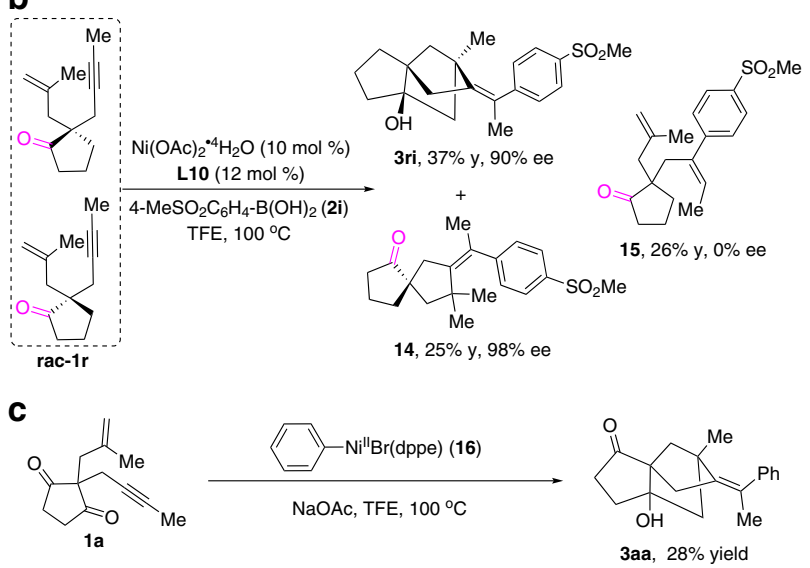

d

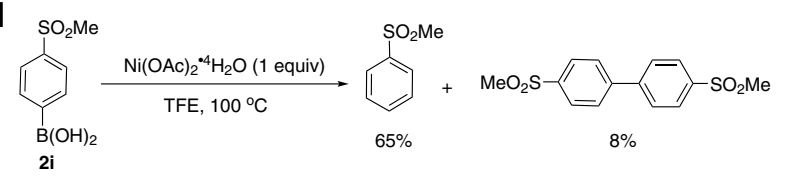

e
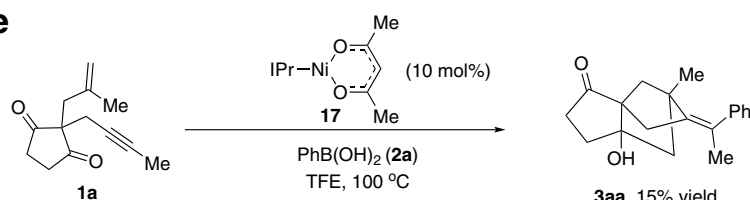

3aa, $15 \%$ yield

Fig. 6 Mechanistic studies. a Three-component reaction with acetone. b The domino reaction used mono-carbonyl enyne substrate. c The use of stoichiometric aryl-Ni(II) complex in the reaction. $\mathbf{d}$ The stoichiometric reaction of $\mathrm{Ni}(\mathrm{OAc})_{2} \cdot 4 \mathrm{H}_{2} \mathrm{O}$ with boronic acid. $\mathbf{e}$ The use of $\mathrm{Ni}(\mathrm{I})$ complex in the reaction.

cleaved by ozonolysis with $\mathrm{O}_{3}$ to give optically pure tricyclic diketone 11 in $80 \%$ yield.

Mechanistic investigation. We conducted preliminary mechanistic experiments to provide insight about the reaction mechanism. The reaction of enyne 12 with $\mathrm{PhB}(\mathrm{OH})_{2}$ in the presence of acetone resulted in a complex of mixture, the expected product $\mathbf{1 3}$ formed through enyne cyclization/intermolecular nucleophilic addition to acetone, was not observed (Fig. 6a). In addition, the reaction of mono-carbonyl enyne $1 \mathbf{r}$ under our standard reaction conditions led to the formation of significant amount of the regioisomeric arylation product 15 (26\% yield, Fig. 6b). These results indicate that these two ketone carbonyl groups on the substrate are very crucial. No enantiomeric excess was detected for product 15, suggesting that the 1,2-addition of arylnickel species to alkyne might not be the turnover-limiting step. The formation of product 3ri and $\mathbf{1 4}$ was likely a kinetic resolution process, where one of the enantiomer of racemic $1 \mathbf{r}$ was transformed to the 3ri in $37 \%$ yield with $90 \%$ ee, while the other was converted to 14 in $25 \%$ yield with $98 \%$ ee. These results clearly demonstrate that the Heck-cyclization process is the enantioselective-determining step of this transformation.

In order to further understand the reaction mechanism and catalytically active species of this transformation, aryl-Ni(II) 


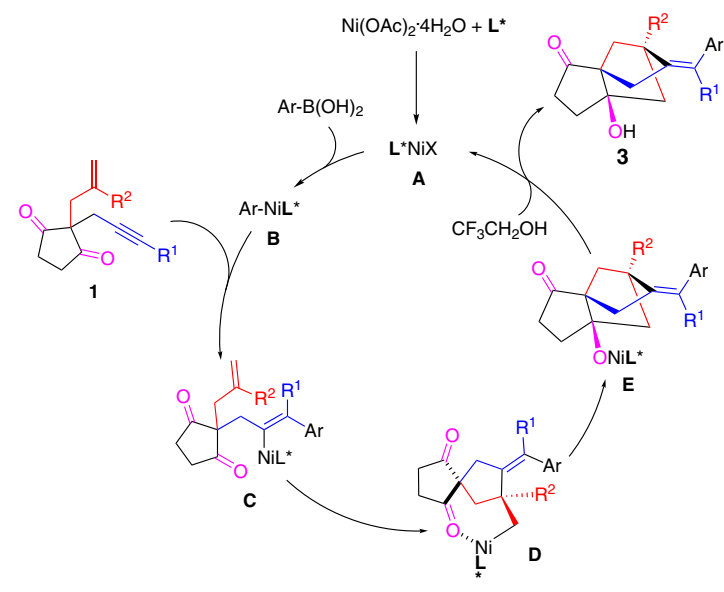

Fig. 7 Reaction mechanism. Proposed catalytic cycle.

complex 16 was prepared $6,58,59$, and the stoichiometric reaction of 16 with 1a afforded $3 \mathrm{aa}$ in $28 \%$ yield (Fig. 6c), implying that aryl-Ni(II) species is involved in the catalytic cycle. We performed a stoichiometric reaction of $\mathrm{Ni}(\mathrm{OAc})_{2} \cdot 4 \mathrm{H}_{2} \mathrm{O}$ (1 equiv) and $2 \mathbf{i}$ ( 1 equiv) in TFE, it was found that in addition to a deboronated product (65\%), a biaryl product was also detected (Fig. 6d). This result indicates that $\mathrm{Ni}(\mathrm{II})$ was reduced to $\mathrm{Ni}(0)$ by reductive elimination of the corresponding diarylnickel(II) intermediate. Therefore, $\mathrm{Ni}(\mathrm{I})$ species may be generated by the disproportionation reaction between $\mathrm{Ni}(\mathrm{II})$ and $\mathrm{Ni}(0)$ species. $\mathrm{IPrNi}(\mathrm{acac}) 17$ was synthesized following the previously reported procedure ${ }^{60}$. This $\mathrm{Ni}(\mathrm{I})$ complex was also found to catalyze the domino cyclization of 1a with $\mathrm{PhB}(\mathrm{OH})_{2}$ to afford 3aa (Fig. 6e), thus indicating that an alternative mechanism involving aryl-Ni(I) species cannot be ruled out.

Proposed reaction mechanism. On the basis of the above results, a possible catalytic cycle for this transformation is proposed in Fig. 7. Transmetallation of arylboronic acid with the chiral nickel species A (X could be acetate, hydroxide or 2,2,2-trifluoroethoxide) gives the arylnickel complex $\mathbf{B}$. The 1,2-addition of arylnickel species to the triple bond to form an alkenylnickel intermediate C. An intramolecular migratory insertion of alkenylnickel $\mathbf{C}$ into double bond affords the $\sigma$-alkylnickel intermediate $\mathbf{D}^{61-64}$. A subsequent nucleophilic cyclization of the resulting $\sigma$-alkylnickel species $\mathbf{D}$ onto one of the ketones leads to nickel alkoxide species $\mathbf{E}$, followed by protonolysis to regenerate the catalytical active nickel catalyst and release the desired tricyclo [5.2.1.0 $0^{1,5}$ ] decane product 3 . The oxidation state of nickel catalyst is still unclear, both $\mathrm{Ni}(\mathrm{I})$ and $\mathrm{Ni}(\mathrm{II})$ are possible.

\section{Discussion}

In summary, a nickel-catalyzed asymmetric domino cyclization of 1,3-diketone tethered 1,6-enynes has been successfully developed, providing a general synthesis of optically pure bridged tricyclo [5.2.1.0 $\left.0^{1,5}\right]$ decanes with three quaternary stereocenters in good yields and remarkable high levels of enantioselectivities (92-99\% ee). This reaction is initiated by a regioselective 1,2-addition of arylboronic acid to the alkyne, followed by an enantioselective Heck-cyclization with unactivated alkene and nucleophilic cyclization of the resulting $\sigma$-alkylnickel species to the ketone group. Preliminary mechanistic studies indicate that either $\mathrm{Ni}(\mathrm{I})$ or $\mathrm{Ni}$ (II) species may be involved in the catalytic cycle.

\begin{abstract}
Methods
Procedure for enantioselective synthesis of bridged tricyclo[5.2.1.01,5]

decanes. To an oven-dried sealed tube equipped with a PTFE-coated stir bar was charged with $\mathrm{Ni}(\mathrm{OAc})_{2} \cdot 4 \mathrm{H}_{2} \mathrm{O}(0.01 \mathrm{mmol}, 10 \mathrm{~mol} \%), 1$ R, I'R,2 S,2'S-Duanphos $(0.012 \mathrm{mmol}, 12 \mathrm{~mol} \%)$ and TFE $(1 \mathrm{~mL})$. This reaction mixture was stirred at room temperature for 15 minutes in an argon-filled glovebox. Enynone $\mathbf{1}(0.1 \mathrm{mmol})$ and (hetero)arylboronic acid $\mathbf{2}(0.2 \mathrm{mmol}, 2$ equiv) was then added. The sealed tube was sealed and removed from the glovebox. Then the mixture was stirred at $100^{\circ} \mathrm{C}$ until the reaction was complete (monitored by TLC). The resulting mixture was concentrated under reduced pressure and purified by column chromatography on silica gel, eluting with petroleum ether/ethyl acetate 5/1 1/1 (v/v) to afford the corresponding product 3 .
\end{abstract}

\section{Data availability}

The authors declare that all the data supporting the findings of this work are available within the article and its Supplementary Information files or from the corresponding author upon request. The X-ray crystallographic coordinates for structures reported in this study have been deposited at the Cambridge Crystallographic Data Centre (CCDC), under deposition numbers 1963288 (3aa). These data can be obtained free of charge from The Cambridge Crystallographic Data Centre via http://www.ccdc.cam.ac.uk/ data_request/cif.

Received: 4 February 2020; Accepted: 30 March 2020;

Published online: 20 April 2020

\section{References}

1. Xu, P. F. \& Wang, W. Catalytic Cascade Reactions (Wiley-VCH, 2013).

2. Tietze, L. F. Multicomponent Domino Process: Rational Design and Serendipity (Wiley-VCH, 2014).

3. Zhou, M. et al. Schincalide A, a schinortriterpenoid with a tricyclo[5.2.1.01,6] decane-bridged system from the stems and leaves of Schisandra incarnate. Org. Lett. 18, 4558-4561 (2016).

4. Ma, S. et al. Illisimonin A, a caged sesquiterpenoid with a tricyclo[5.2.1.01,6] decane skeleton from the Fruits of Illicium simonsii. Org. Lett. 19, 6160-6163 (2019).

5. Ihara, M. \& Fukumoto, K. Syntheses of polycyclic natural products employing the intramolecular double michael reaction. Angew. Chem. Int. Ed. 32, 1010-1022 (1993)

6. Ihara, M., Makita, K. \& Takasu, K. Facile construction of the tricyclo [5.2.1.01,5] decane ring system by intramolecular double michael Reaction: highly stereocontrolled total synthesis of $( \pm$ )-8,14-cedranediol and $( \pm)-8,14$ cedranoxide. J. Org. Chem. 64, 1259-1264 (1999).

7. Takasu, K., Mizutani, S., Noguchi, M., Makita, K. \& Ihara, M. Stereocontrolled total synthesis of $( \pm)$-culmorin via the intramolecular double michael Addition. Org. Lett. 1, 391-394 (1999).

8. Burns, A. S. \& Rychnovsky, S. D. Total synthesis and structure revision of (-)-illisimonin A, a neuroprotective sesquiterpenoid from the fruits of Illicium simonsii. J. Am. Chem. Soc. 141, 13295-13330 (2019).

9. Jamison, T. F., Shambayati, S., Crowe, W. E. \& Schreiber, S. L. Cobaltmediated total synthesis of (+)-epoxydictymene. J. Am. Chem. Soc. 116, 5505-5506 (1994).

10. Seiple, I. B. et al. Total synthesis of palau'amine. Angew. Chem. Int. Ed. 49, 1095-1098 (2010).

11. Pronin, S. V. \& Shenvi, R. A. Synthesis of highly strained terpenes by non-stop tail-to-head polycyclization. Nat. Chem. 4, 915-920 (2012).

12. Hu, P. \& Snyder, S. A. Enantiospecific total synthesis of the highly strained (-)-presilphiperfolan-8-ol via a Pd-catalyzed tandem cyclization. J. Am. Chem. Soc. 139, 5007-5010 (2017).

13. Chen, W.-W. \& Xu, M.-H. Recent advances in rhodium-catalyzed asymmetric synthesis of heterocycles. Org. Biomol. Chem. 15, 1029-1050 (2017).

14. Cao, P. \& Zhang, X. The first highly enantioselective Rh-catalyzed enyne cycloisomerization. Angew. Chem. Int. Ed. 39, 4104-4106 (2000).

15. Lei, A., He, M. \& Zhang, X. Highly enantioselective syntheses of functionalized $\alpha$-methylene- $\gamma$-butyrolactones via $\mathrm{Rh}(\mathrm{I})$-catalyzed intramolecular alder ene reaction: application to formal synthesis of (+)-pilocarpine. J. Am. Chem. Soc. 124, 8198-8199 (2002).

16. Park, J. H., Kim, S. M. \& Chung, Y. K. Rh-catalyzed reductive cyclization of enynes using ethanol as a source of hydrogen. Chem. Eur. J. 17, 10852-10856 (2011).

17. Shen, K., Han, X. \& Lu, X. Cationic Pd(II)-catalyzed highly enantioselective arylative cyclization of alkyne-tethered enals or enones initiated by carbopalladation of alkynes with arylboronic acids. Org. Lett. 14, 1756-1759 (2012). 
18. He, Z. et al. Rhodium-catalyzed asymmetric arylative cyclization of meso-1,6dienynes leading to enantioenriched cis-hydrobenzofurans. Angew. Chem. Int. Ed. 52, 5314-5318 (2013).

19. Keilitz, J., Newman, S. G. \& Lautens, M. Enantioselective Rh-catalyzed domino transformations of alkynylcyclohexadienones with organoboron reagents.Org. Org. Lett 15, 1148-1151 (2013).

20. Masutomi, K., Noguchi, K. \& Tanaka, K. Enantioselective cycloisomerization of 1,6-enynes to bicyclo[3.1.0] hexanes catalyzed by rhodium and benzoic acid. J. Am. Chem. Soc. 136, 7627-7630 (2014).

21. Trost, B. M., Ryan, M. C., Rao, M. \& Markovic, T. Z. Construction of enantioenriched [3.1.0] bicycles via a ruthenium-catalyzed asymmetric redox bicycloisomerization reaction. J. Am. Chem. Soc. 136, 17422-17425 (2014).

22. Serpier, F., Flamme, B., Brayer, J., Folleas, B. \& Darses, S. Chiral pyrrolidines and piperidines from enantioselective rhodium-catalyzed cascade arylative cyclization. Org. Lett. 17, 1720-1723 (2015).

23. Deng, X. et al. Enantioselective rhodium-catalyzed cycloisomerization of (E)1,6-enynes. Angew. Chem. Int. Ed. 55, 6295-6299 (2016).

24. Oonishi, Y., Masusaki, S., Sakamoto, S. \& Sato, Y. Rhodium(I)-catalyzed enantioselective cyclization of enynes by intramolecular cleavage of the Rh-C bond by a tethered hydroxy group. Angew. Chem. Int. Ed. 58, 8736-8379 (2019).

25. Selmani, A. \& Darses, S. Access to chiral cyano-containing five-membered rings through enantioconvergent rhodium-catalyzed cascade cyclization of a diastereoisomeric E/Z mixture of 1,6-enynes. Org. Chem. Front. 6, 3978-3982 (2019).

26. Montgomery, J. Nickel-catalyzed cyclizations, couplings, and cycloadditions involving three reactive components. Acc. Chem. Res. 33, 467-473 (2000)

27. Montgomery, J. Nickel-catalyzed reductive cyclizations and couplings. Angew. Chem. Int. Ed. 43, 3890-3908 (2004).

28. Clarke, C., Incerti-Pradillos, C. A. \& Lam, H. W. Enantioselective nickelcatalyzed anti-carbometallative cyclizations of alkynyl electrophiles enabled by reversible alkenylnickel E/Z isomerization. J. Am. Chem. Soc. 138, 8068-8071 (2016).

29. Lautens, M. \& Mancuso, J. Formation of homoallyl stannanes via palladiumcatalyzed stannylative cyclization of enynes. Org. Lett. 2, 671-673 (2000).

30. Marco-Martínez, J., López-Carrillo, V., Buñuel, E., Simancas, R. \& Cárdenas, D. J. Pd-catalyzed borylative cyclization of 1,6-enynes. J. Am. Chem. Soc. 129, 1874-1875 (2007).

31. Yang, C., Mannathan, S. \& Cheng, C.-H. Nickel-catalyzed chemo- and stereoselective alkenylative cyclization of 1,6-enynes with alkenyl boronic acids. Chem. Eur. J. 19, 12212-12216 (2013).

32. Cabrera-Lobera, N., Rodríguez-Salamanca, P., Nieto-Carmona, J. C., Buñuel, E. \& Cárdenas, D. J. Iron-catalyzed hydroborylative cyclization of 1,6-enynes. Chem. Eur. J. 24, 784-788 (2018).

33. Hsieh, J.-C., Hong, Y.-C., Yang, C.-M., Mannathan, S. \& Cheng, C.-H. Nickelcatalyzed highly chemo- and stereoselective borylative cyclization of 1,6enynes with bis(pinacolato)diboron. Org. Chem. Front. 4, 1615-1619 (2017).

34. Moslin, R. M., Miller-Moslin, K. \& Jamison, T. F. Regioselectivity and enantioselectivity in nickel-catalysed reductive coupling reactions of alkynes. Chem. Commun. 2007, 4441-4449 (2007).

35. Miura, T. \& Murakami, M. Formation of carbocycles through sequential carborhodation triggered by addition of organoborons. Chem. Commun. 2007, 217-224 (2007).

36. Iida, H. \& Krische, M. J. Catalytic reductive coupling of alkenes and alkynes to carbonyl compounds and imines mediated by hydrogen. Top. Curr. Chem. 279, 77-104 (2007)

37. Skucas, E., Ngai, M.-Y., Komanduri, V. \& Krische, M. J. Enantiomerically enriched allylic alcohols and allylic amines via $\mathrm{C}-\mathrm{C}$ bond-forming hydrogenation: asymmetric carbonyl and imine vinylation. Acc. Chem. Res. 40, 1394-1401 (2007).

38. Jeganmohan, M. \& Cheng, C.-H. Cobalt- and nickel-catalyzed regio- and stereoselective reductive coupling of alkynes, allenes, and alkenes with alkenes. Chem. Eur. J. 14, 10876-10886 (2008).

39. Malik, H. A., Baxter, R. D. \& Montgomery, J. in Catalysis Without Precious Metals (ed. Bullock, R. M.) 181 (Wiley-VCH, 2010).

40. Tian, P., Dong, H. \& Lin, G.-Q. Rhodium-catalyzed asymmetric arylation. ACS Catal. 2, 95-119 (2012).

41. Jackson, E. P. et al. Mechanistic basis for regioselection and regiodivergence in nickel-catalyzed reductive couplings. Acc. Chem. Res. 48, 1736-1745 (2015).

42. Standley, E. A., Tasker, S. Z., Jensen, K. L. \& Jamison, T. F. Nickel catalysis: synergy between method development and total synthesis. Acc. Chem. Res. 48, 1503-1514 (2015).

43. Song, J., Shen, Q., Xu, F. \& Lu, X. Cationic Pd(II)-catalyzed enantioselective cyclization of aroylmethyl 2-alkynoates initiated by carbopalladation of alkynes with arylboronic acids. Org. Lett. 9, 2947-2950 (2007).
44. Han, X. \& Lu, X. Control of chemoselectivity by counteranions of cationic palladium complexes: a convenient enantioselective synthesis of dihydrocoumarins. Org. Lett. 12, 108-111 (2010).

45. Li, Y. \& Xu, M.-H. Rhodium-catalyzed asymmetric tandem cyclization for efficient and rapid access to underexplored heterocyclic tertiary allylic alcohols containing a tetrasubstituted olefin. Org. Lett. 16, 2712-2715 (2014).

46. Johnson, T., Choo, K.-L. \& Lautens, M. Rhodium-catalyzed arylative cyclization for the enantioselective synthesis of (trifluoromethyl) cyclobutanols. Chem. Eur. J. 20, 14194-14197 (2014).

47. Fu, W., Nie, M., Wang, A., Cao, Z. \& Tang, W. Highly enantioselective nickelcatalyzed intramolecular reductive cyclization of alkynones. Angew. Chem. Int. Ed. 54, 2520-2524 (2015).

48. Yan, J. \& Yoshikai, N. Cobalt-catalyzed arylative cyclization of acetylenic esters and ketones with arylzinc reagents through 1,4-cobalt migration. ACS Catal. 6, 3738-3742 (2016).

49. Karad, S. N., Panchal, H., Clarke, C., Lewis, W. \& Lam, H. W. Enantioselective synthesis of chiral cyclopent-2-enones by nickel-catalyzed desymmetrization of malonate esters. Angew. Chem. Int. Ed. 57, 9122-9125 (2018).

50. Selmani, A. \& Darses, S. Enantioenriched 1-tetralones via rhodium-catalyzed arylative cascade desymmetrization/acylation of alkynylmalonates. Org. Lett. 21, 8122-8126 (2019).

51. Ramachary, D. B. \& Kishor, M. Direct amino acid-catalyzed cascade biomimetic reductive alkylations: application to the asymmetric synthesis of Hajos-Parrish ketone analogues.Org. Biomol. Chem. 6, 4176-4187 (2008).

52. Cuadros, S., Dell'Amico, L. \& Melchiorre, P. Forging fluorine-containing quaternary stereocenters by a light-driven organocatalytic aldol desymmetrization process. Angew. Chem. Int. Ed. 56, 11875-11879 (2017)

53. Liu, D. \& Zhang, X. Practical P-chiral phosphane ligand for Rh-catalyzed asymmetric hydrogenation. Eur. J. Org. Chem. 2005, 646-649 (2005).

54. Wu, X.-F. \& Wang, Z.-C. Transition Metal Catalyzed Pyrimidine, Pyrazine, Pyridazine and Triazine Synthesis 1st edn (Elsevier, 2017).

55. Tsuri, T. et al. Bicyclo[2.2.1]heptane and 6,6-dimethylbicyclo[3.1.1]heptane derivatives: orally active, potent, and selective prostaglandin $\mathrm{D} 2$ receptor antagonists. J. Med. Chem. 40, 3504-3507 (1997).

56. Mitsumori, S. et al. Synthesis and biological activity of various derivatives of a novel class of potent, selective, and orally active prostaglandin D2 receptor antagonists. 1. bicyclo[2.2.1] heptane derivatives. J. Med. Chem. 46, 2436-2445 (2003).

57. Ohno, M. et al. Nucleotide analogues containing 2-oxa-bicyclo[2.2.1]heptane and 1- $\alpha$-threofuranosyl ring systems: interactions with P2Y receptors. Bioorg. Med. Chem. 12, 5619-5630 (2004).

58. Traina, C. A., Bakus, R. C. \& Bazan, G. C. Rhodium-catalyzed antimarkovnikov intermolecular hydroalkoxylation of terminal acetylenes. J. Am. Chem. Soc. 133, 32-34 (2011).

59. Senkovskyy, V. et al. "hairy" poly(3-hexylthiophene) particles prepared via surface-initiated kumada catalyst-transfer polycondensation. J. Am. Chem. Soc. 131, 16445-16453 (2009).

60. Zhang, X., Xie, X. \& Liu, Y. Nickel-catalyzed cyclization of alkyne-nitriles with organoboronic acids involving anti-carbometalation of alkynes. Chem. Sci. 7, 5815-5820 (2016).

61. Ping, Y., Li, Y., Zhu, J. \& Kong, W. Construction of quaternary stereocenters by palladium-catalyzed carbopalladation-initiated cascade reactions. Angew. Chem. Int. Ed. 58, 1562-1573 (2019).

62. Wang, K., Ding, Z., Zhou, Z. \& Kong, W. Ni-catalyzed enantioselective reductive diarylation of activated alkenes by domino cyclization/cross-couplin. J. Am. Chem. Soc. 140, 12364-12368 (2018).

63. Ping, Y. et al. Ni-catalyzed regio- and enantioselective domino reductive cyclization: one-pot synthesis of 2,3-fused cyclopentannulated indolinesg. ACS Catal. 9, 7335-7342 (2019).

64. Qin, X., Lee, M. W. Y. \& Zhou, J. S. Nickel-catalyzed asymmetric reductive Heck cyclization of aryl halides to afford indolines. Angew. Chem. Int. Ed. 56, 12723-12726 (2017).

\section{Acknowledgements}

We thank to Prof. J. Zhu (Ecole polytechnique fédérale de Lausanne) for their helpful discussion. This work was supported by NSFC (21702149), "1000-Youth Talents Plan", Wuhan University and Fundamental Research Funds for the Central Universities (2042018kf0012).

\section{Author contributions}

W.K. conceived and designed the project. W.K. and J.C. designed the experiments. J.C., Z.D., and Y.W. performed the experiments and analyzed the data. W.K. prepared the manuscript. All authors contributed to discussions. 


\section{Competing interests}

The authors declare no competing interests.

\section{Additional information}

Supplementary information is available for this paper at https://doi.org/10.1038/s41467020-15837-1.

Correspondence and requests for materials should be addressed to W.K.

Peer review information Nature Communications thanks Rambabu Chegondi and the other, anonymous, reviewer(s) for their contribution to the peer review of this work.

Reprints and permission information is available at http://www.nature.com/reprints

Publisher's note Springer Nature remains neutral with regard to jurisdictional claims in published maps and institutional affiliations. (c) (P) Open Access This article is licensed under a Creative Commons Attribution 4.0 International License, which permits use, sharing, adaptation, distribution and reproduction in any medium or format, as long as you give appropriate credit to the original author(s) and the source, provide a link to the Creative Commons license, and indicate if changes were made. The images or other third party material in this article are included in the article's Creative Commons license, unless indicated otherwise in a credit line to the material. If material is not included in the article's Creative Commons license and your intended use is not permitted by statutory regulation or exceeds the permitted use, you will need to obtain permission directly from the copyright holder. To view a copy of this license, visit http://creativecommons.org/ licenses/by/4.0/.

(C) The Author(s) 2020 